Synergies in Social Protection : Impacts of India's MGNREGA and Public Distribution System on the health and nutrition of Women and Children

Sudha Narayanan, Karthikeya Naraparaju, Nicolas Gerber

Indira Gandhi Institute of Development Research, Mumbai December 2019 


\title{
Synergies in Social Protection : Impacts of India's MGNREGA and Public Distribution System on the health and nutrition of Women and Children
}

\author{
Sudha Narayanan, Karthikeya Naraparaju, Nicolas Gerber
}

Email(corresponding author): sudha@igidr.ac.in

\begin{abstract}
This paper examines whether participation in workfare and food grain subsidy programs in India impacts health and nutritional status of women and children in participating households, using short-term morbidity and body mass index (BMI) as indicators. Using the Indian Human Development Survey (IHDS), a nationally representative panel data survey conducted in 2005 and 2012, we estimate average treatment effects for participants using a semi-parametric differences-in-differences and a regression-based DID using a sample matched on the propensity scores. We find that participation in these programs lowers morbidity for women by upto $28 \%$. We also find evidence, though statistically weaker, that participation increases women's BMI, at least in states implementing those programs well. For children, we find generally positive impacts of household participation in these programs on their $B M I$, however there is no robust evidence of any impact on their morbidity. Our results suggest that social protection programs can operate synergistically and deliver positive impacts on children and women's nutrition or health, even though this is not their main objective. At the same time, the effects are heterogeneous, confirming that benefits of programs are mediated by intrahousehold dynamics.
\end{abstract}

Keywords: social protection, employment guarantee, food subsidy, morbidity, BMI, India

JEL Code: I1, I18, I38, J08

\footnotetext{
Acknowledgements:

The research leading to this paper has received funding from the European Union's Seventh Framework Programs FP7/2007-2011 under Grant Agreement $n^{\circ} 290693$ FOODSECURE. Neither the FOODSECURE project, its partner organizations, nor any organization of the European Union or European Commission are accountable for the content of papers in this series. We thank without implicating S.Mahendra Dev and participants at seminars in Bonn, Mumbai and Montreal for comments and suggstions. We also thank Priya Rampal and Sanchita Roychowdhury for valuable research assistance. Detailed results are available from the authors.
} 


\title{
Synergies in Social Protection \\ Impacts of India's MGNREGA and Public Distribution System \\ on the health and nutrition of Women and Children ${ }^{1}$
}

Sudha Narayanan, Karthikeya Naraparaju, Nicolas Gerber ${ }^{2}$

\begin{abstract}
This paper examines whether participation in workfare and food grain subsidy programs in India impacts health and nutritional status of women and children in participating households, using short-term morbidity and body mass index (BMI) as indicators. Using the Indian Human Development Survey (IHDS), a nationally representative panel data survey conducted in 2005 and 2012, we estimate average treatment effects for participants using a semi-parametric differences-in-differences and a regression-based DID using a sample matched on the propensity scores. We find that participation in these programs lowers morbidity for women by upto $28 \%$. We also find evidence, though statistically weaker, that participation increases women's BMI, at least in states implementing those programs well. For children, we find generally positive impacts of household participation in these programs on their BMI, however there is no robust evidence of any impact on their morbidity. Our results suggest that social protection programs can operate synergistically and deliver positive impacts on children and women's nutrition or health, even though this is not their main objective. At the same time, the effects are heterogeneous, confirming that benefits of programs are mediated by intrahousehold dynamics.
\end{abstract}

Keywords: social protection, employment guarantee, food subsidy, morbidity, BMI, India

JEL Classification: I1, I18, I38, J08

\footnotetext{
${ }^{1}$ The research leading to this paper has received funding from the European Union's Seventh Framework Programs FP7/2007-2011 under Grant Agreement n 290693 FOODSECURE. Neither the FOODSECURE project, its partner organizations, nor any organization of the European Union or European Commission are accountable for the content of papers in this series. We thank without implicating S.Mahendra Dev and participants at seminars in Bonn, Mumbai and Montreal for comments and suggstions. We also thank Priya Rampal and Sanchita Roychowdhury for valuable research assistance. Detailed results are available from the authors.

${ }^{2}$ Sudha Narayanan is Associate Professor at the Indira Gandhi Institute of Development Research, Mumbai. Karthikeya Naraparaju is Assistant Professor, Indian Institute of Managament (IIM), Indore. Nicolas Gerber is Senior Researcher, Zentrum fur Entwicklungs Forschung (ZEF) Bonn. Corresponding author: Sudha Narayanan sudha@igidr.ac.in
} 


\section{Background}

Ever since the adoption of the Sustainable Development Goals (SDGs) in 2015, there has been considerable attention devoted to conceptualizing and operationalizing interlinkages between the SDGs, so that social policy can operate in a more holistic or integrated way (UN 2018). There is increasing recognition that large-scale social protection programs can decrease risks associated with livelihoods of the poor (Kanbur, 2015) and thus contribute to putting these synergies into practice. Development cooperation actors and researchers have indeed identified the role of social protection in influencing a number of the SDG targets at once, even if the specific goals of the programs are somewhat narrow (BMZ, 2017; Cluver et al., 2016). Social policy in developing countries encompasses a wide range of programs designed to alleviate poverty, protect incomes, smooth consumption and augment human capital investment. These programs can thus have varying goals, target groups and can take different forms, for example, cash transfers (with or without conditionalities), insurance, workfare programs, food aid and subsidies. While there is a rich body of evidence on whether these schemes effectively target the poor and whether they fulfil their stated objectives, there is comparatively less literature on the synergistic potential of these programs to promote SDG goals that are not overtly the objective of these programs (See Ruel and Alderman (2013), for example, on the nutrition sensitivity of social protection programs). Even less is known about whether the convergence of benefits from different programs to a single household accrues equitably to all household members, especially to women and children.

In this paper, we investigate whether large-scale social protection programs that purportedly focus on alleviating poverty and hunger (SDGs 1 and 2, especially targets 1.1, 11.2, 1.3, and 2.1), can have synergistic impacts on health (SDG3) and nutrition (SDG 2, target 2.2) as well, and in ways that forward gender equality (SDG 5). To that effect, we analyze the health and nutrition impacts of two large-scale social safety nets in India: a workfare program, the Mahatma Gandhi National Rural Employment Guarantee Act (MGNREGA), and the in-kind distribution of subsidized foodgrain, the Public Distribution System (PDS), on select aspects of health and nutrition. Specifically, we ask: are these programs also 'nutrition sensitive' even though health and nutrition are not intended outcomes? Can participation in both programs deliver synergistic benefits? Do these household-focussed interventions 
have the ability to reach vulnerable members within the household, especially women and children?

The MGNREGA is among the largest public works programs in the world. Rolled out in three phases over the years 2006 to 2008, it guarantees, in principle, each rural household a minimum of 100 days of manual, unskilled work on demand for wages established according to the task undertaken. It has generated more than 28 billion person days of work and expenditure of US\$78 billion since its inception. ${ }^{3}$ Prior to the MGNREGA, there were workfare programs in place, for example, the Food for Work (FFW) program and the Sampoorna Gramin Rozgar Yojana (SGRY), which were replaced eventually by the MGNREGA. However, the SGRY/FFW did not have any special provisions to encourage women's participation. The MGNREGA in contrast, has often been regarded as a women's program for the high participation of women; it also contains several elements that fosters such participation - it offers women equal wages, mandates that one-third of the beneficiaries be women, mandates that work be provided in the village, and so on (see Holmes, et al, 2011; Khera and Nayak, 2009, Narayanan and Das, 2014 for example). While functioning as a labour market intervention and safety net for rural families, it therefore also has a potential to benefit women in particular.

The PDS is the largest subsidized food grain distribution scheme in the world, with an allocation of 58.55 million tonnes of food grains across various welfare schemes during the year in 2018-19. It has been operational since the 1960s and has continued with some major changes in the 1990s that involved targeting the poor as opposed to universal coverage. Most recently, it has figured prominently in the National Food Security Act (NFSA) 2013, an Act that seeks to cover two-thirds of the population of the country, $75 \%$ in rural areas and $50 \%$ in urban areas. The program involves entitlements of rice and wheat, with pulses, sugar and oil provided additionally in several states, at subsidized rates. There is considerable variation across states in terms of entitlements and prices, with some states implementing a universal entitlement scheme and others restricting beneficiaries.

Nationally representative data in India suggest that in 2011-12, around half of all rural households were buying some rice or wheat from the PDS and close to a

\footnotetext{
${ }^{3}$ Days generated are as on April 28, 2019 and expenditures are cumulated in nominal terms valued at the exchange rate of Rs.65=US\$1.

http://mnregaweb4.nic.in/netnrega/all_lvl_details_dashboard_new.aspx published on March 14, 2017.
} 
quarter of all rural households had at least one member who had worked for at least one day on the MGNREGA during the year preceding the date of the survey (Narayanan and Gerber, 2017; Table 1).

Recent literature documents wide-ranging impacts of these two programs, notably on consumption expenditure, food intake, wages, etc., but only a few focus on on health and nutritional impacts (reviewed, for example, in Sukhtankar, 2016; Puri, et al., 2017; Narayanan and Gerber, 2017 and Pingali et al., 2017). Even fewer focus on the synergies between the two programs, given that the poor often benefit from both programs. This paper is a contribution to understanding better the implications of the combined impact of these two social protection programs on nutrition and health for women and children.

The paper uses data from the Indian Human Development Survey (IHDS), a rich panel that captures anthropometric and morbidity indicators as well as PDS and MGNREGA participation, to understand the nature of the relationship between these safety nets and the health and nutrition of individuals. The IHDS provides household level PDS consumption, individual level participation in the MGNREGA, as well as nutritional and morbidity status of individuals at two points of time in 2005 and 2012. The first round provides a baseline because it preceded MGNREGA implementation; the PDS was however already in place at that time as were other workfare programs such as the SGRY. Over this period, there has been a substantial improvement in extending PDS' coverage during the period 2005 and 2012 (Khera, 2011a; Rahman, 2014). We also observe this in our sample. ${ }^{4} \mathrm{We}$ attempt to estimate causal impacts of these programs, recognizing the presence of a large number of confounders.

Essentially, we ask if women and children in households that utilize both the PDS and MGNREGA fare better in terms of health and nutritional status than if they had not. There is considerable evidence today suggesting that household benefits are not necessarily evenly distributed across household members and that norms and practices governing intra-household allocation could leave women in the household

\footnotetext{
${ }^{4}$ According to the National Sample Survey, between 2004-05 nd 2011-12, the percentage of households reporting consumption of rice from PDS rose sharply from 24.4 per cent to 39 per cent in rural areas. The percentage of such families consuming rice increased from 13 per cent to 20.5 per cent during the period. For wheat and wheat flour, the share of households accessing the PDS rose from from 11 per cent to 27.6 per cent and 5.8 to 17.6 per cent in rural and urban areas respectively.
} 
worse off (Brown, et al, 2019; Brown, et al., forthcoming; Lentz et al, 2019). In the same vein, development literature identifies earnings accruing to women in the household as empowering and note that women often direct earnings from social safety nets to human capital investment (which would reflect in children's well-being for instance). This aspect is particularly interesting in the context of the MGNREGA where wages accrue to individuals.

In focussing on health and nutrition outcomes of women and children in participant households, we ignore the possibility that there might be spillover or general equilibrium impacts on non-participants as well. These could be positive (if for instance, the MGNREGA pushes up wage rates overall) or negative (if for instance, PDS increases food prices overall or promotes food grain, at the cost of dietary diversity). ${ }^{5}$ Nor are we able to comment on the direction of impacts for adult men, for whom we do not have comparable data. These remain limitations of the analysis.

The rest of this paper is organized into 5 sections. Following this introduction, we present the conceptual pathways through which these schemes can potentially impact health and nutrition. In Section 3, we discuss the data, empirical strategy and broadly the methods. Section 4 presents the results. In section 5, we present a set of robustness checks we implemented. The final Section 6 concludes the discussion.

\section{Conceptual Pathways}

There are two potentially opposing pathways through which the MGNREGA and PDS might influence health and nutritional status (Narayanan and Gerber, 2016). A household's participation in the MGNREGA augments incomes through wage as long as it does not crowd out private employment; similarly, accessing food grains at subsidized prices from the PDS represents an implicit transfer that frees income that might have otherwise been directed to food grains. The income thus gained or saved could then be used for investments in improving children's health such as child immunization, institutional delivery of mothers, their antenatal and postnatal care, etc. as well as to improve the household's access to other amenities such as drinking

\footnotetext{
${ }^{5}$ There is little evidence on the general equilibrium effects of the PDS. In contrast there is more evidence on the wage impacts of the MGNREGA.
} 
water, toilet, electricity, clean cooking fuel, healthcare services, etc., that could also influence the health and nutritional outcomes of the household members. ${ }^{6}$

On the other hand, to the extent that the MGNREGA attracts women's work effort, it could crowd out time spent on seeking healthcare for themselves. To the extent that women are primary care givers for children in the household, this can adversely impact childcare as well. Further, since the MGNREGA work involves substantial physical effort, if it is not compensated with adequate intake of calories it could leave adults worse off. This is especially a concern given the well-documented phenomenon of substantial delay in paying wages to the MGNREGA workers (Khera, 2011b) and the fairly low wages offered to program participants. Similarly, if access to subsidized food grains through PDS crowds out, rather than crowd in, a diverse food basket, this would have negative consequences for some aspects of health. Thus, the pathways through which the MGNREGA and PDS can impact health outcomes can have counterbalancing effects. These pathways are further mediated by intrahousehold allocation of resources, given that both the MGNREGA and PDS are entitlements at the household level, even if the MGNREGA wages accrue to the individual worker.

Studies of these two programs have thus far tended to focus on intermediary outcomes (like food consumption, or time spent on child care, for instance) often at the household level. Those that assess impacts on nutritional status do so for particular subpopulations (such as children) in specific geographies (Gaiha et al., 2010,; Thampi, 2016; Dasgupta, 2017). Some estimate catch-all effects of program scale at the district level of both the MGNREGA and PDS on individual health outcomes of those in the district, but have little to say about the impact on participant households relative to nonparticipant households (Narayanan et al., 2017). There are also studies that, like us, use the IHDS data, focussing however on one or the other program rather than both. These find that the PDS has limited or no impact on Body Mass Index (BMI) (Desai and Vanneman 2015). It appears too that the effects are apparent in some states but not in others (Thampi, 2016). Sharma (2015) uses the second round of IHDS data and finds that MGNREGA participation reduces children's morbidity. Our analysis expands the set of questions to include both

\footnotetext{
${ }^{6}$ These benefits would naturally manifest only if there is access to reliable infrastructure that supports good health and nutrition outcomes.
} 
MGNREGA and PDS participation and potential synergies between them and the differential impacts on women and children.

\section{Methods}

\subsection{The Survey}

The India Human Development Survey (IHDS) is a nationally representative, multi-topic survey of 41,554 households in 1503 villages and 971 urban neighborhoods across India. The first round of interviews, The India Human Development Survey-I (IHDS-I), was completed in 2004-5. In 2011-12, in the second round, IHDS-II, about 85 percent of the households covered in the 2004-05 round were reinterviewed. ${ }^{7}$ IHDS-II covered 42,152 households in 1,503 villages and 971 urban neighborhoods across India. Two one-hour interviews in each household covered topics concerning health, education, employment, economic status, marriage, fertility, gender relations, social capital, village infrastructure, wage levels, among others. $^{8}$

With respect to the causal variables of interest to us, both rounds of the IHDS survey capture household access to food grains distributed through the PDS while the 2011-12 round captures participation in the MGNREGA scheme at the individual level. The 2004-05 round captures an individual's participation in the SGRY and Food-for-work programs. ${ }^{9}$ Based on this, we classify households as participating in the MGNREGA program if at least one member of the household has worked in the program for at least a day in the year preceding the date of the survey. In extensions of the main analysis we also use the number of days of participation to account for the extent of participation. We define a household as accessing PDS if it has purchased any quantity of rice, wheat, sugar or other cereals in the past 30 days prior to the date of the survey. As mentioned before, although the PDS was already in place during

\footnotetext{
${ }^{7}$ As per the survey documents, "all of the 2004-05 households residing in the same village or urban neighborhood were re-interviewed. When households had divided, all split households were reinterviewed if located in the same village/neighborhood. In the case of some urban PSUs where it was difficult to re-contact sufficient households, additional new households were randomly sampled and interviewed. "Source: http://www.icpsr.umich.edu/icpsrweb/DSDR/studies/36151. Accessed on December 12, 2016.

${ }^{8}$ http://www.ihds.umd.edu/. Accessed October 20, 2016.

${ }^{9}$ Very few households have participated in SGRY/ Food for work. For the women sample this accounts for $0.38 \%$ of all observations in 2005 and for the children's sample, this accounts for $0.52 \%$ of all observations in 2005 .
} 
IHDS-I, its reach expanded considerably by 2012, when IHDS-II was undertaken. For example, the proportion of women who live in a household which has access to PDS has increased from $36.16 \%$ in 2005 to $58.63 \%$ in 2012 . In the children's sample, this proportion increased from $27.21 \%$ in 2005 to $51.08 \%$ in 2012 . We identify four categories of households - those that access both the MGNREGA and the PDS, those that access either program but not both and those that access neither, so that we have four mutually exclusive categories of sample households.

Since our focus is on the synergies across the two programs, we conceptualize a treated household as one that accesses both programs. Treatment is defined at the household level because of difficulties in apportioning the PDS entitlements to different members of the household. The comparison group here includes households that use either of the two programs but not both, or those that use neither program. This comparison would therefore yield estimates of the combined impacts of PDS and the MGNREGA.

The chief outcomes of interest are BMI and morbidity for individuals. We use morbidity - number of days of short-term illness in the month preceding the date of the survey as a proxy of health status and the Body Mass Index (BMI) as a proxy for nutritional status. Both measures are somewhat coarse indicators but are widely used in survey based research. The BMI is typically used as a screening and not diagnostic metric. At the same time, it is a popular indicator to measure nutritional status of adults for a variety of reasons. First, it captures the whole spectrum of nutrition, from thinness to overweight to obesity and serves as a reasonably good proxy for macronutrient adequacy. In developing countries such as India, there is substantial evidence that low BMI is correlated with low physical work capacity, higher mortality (Satyanarayana et al., 1991), higher morbidities, and a lower income (Deolalikar A, 1988). Low BMI in women impacts reproductive outcomes. Women with a low BMI tend to give birth to a greater proportion of low birth weight babies compared with those of normal BMI (Kulkarni, et al., 2006, for example). Short-term morbidity involves subjective assessments of one's own health. One concern is that this might be measured with error; however, the longitudinal nature of the dataset redresses to some extent the concern about systematic differences across individuals with respect 
to self-reported morbidity. That said, this study inherits limitations of data availability that pervades literature in this field. ${ }^{10}$

The IHDS surveys collected anthropometric data for children and adolescents (i.e. those aged between 0 and 19 for the years 2011-12 and 2004-05). To maintain the panel structure, we consider data only for those who are aged between 0 and 15 years in both the rounds. Using the WHO guidelines, we construct Z-scores for BMIfor-Age (BAZ) for these individuals ${ }^{11}$, excluding individuals whose BAZ is deemed implausible according to the WHO guidelines and those whose BAZ was missing for one or both the years. This left us with 15,408 observations $(7,704$ for each year) of children aged between 0 to 15 years in both the years. To maintain a consistent sample, we restrict our analysis of the morbidity outcome also to these 15,408 observations for whom the BAZ is also available.

The IHDS also captures the anthropometric data for 'eligible' women who are defined as those who were ever married and are in the age group of 15-49 years. Evermarried women who were interviewed in IHDS-I "but were no longer eligible i.e. older than 49 years of age" were interviewed as well. ${ }^{12}$ We focus on women who were interviewed in both rounds, for whom BMI was recorded in both rounds. We dropped 160 women, whose BMI is implausible as per WHO norms. Consequently, the analysis was conducted on 32,964 observations for women (i.e. 16,482 individuals per year). As with the children's sample, we restrict our analysis of the morbidity outcome to these 16,482 women for whom the BMI is also available.

\subsection{Summary Statistics}

In the children's sample in 2012, there are $1255(16.29 \%)$ children who belong to households accessing both PDS and MGNREGA, 2680 (34.79\%) children belong to households who have access to only PDS, $674(8.75 \%)$ belonging to those households who access only MGNREGA and 3095 (40.17\%) children who have access to neither of these two programs. In the women's sample in 2012, there are

\footnotetext{
${ }^{10}$ One concern is that morbidity is likely to be influenced by the season in which the individual is surveyed both within a round as well as across the two rounds. We account for this seasonality by controlling for the quarter of the calendar year in which the survey was conducted in the estimation.

${ }^{11}$ We use the STATA igrowup package for calculating the BAZ scores for those aged 0- less than 5 years; and WHO Reference 2007 package for the BAZ scores for those aged 5 or above.

12 IHDS 2011-12 User Guide, pg. 8.
} 
2764 individuals (16.77\%) who belong to households accessing both PDS and MGNREGA, 6900 (41.86\%) belonging to households who access only PDS, 996 (6.04\%) belonging to those households who access only MGNREGA and 5822 (35.32\%) who have access to neither of these two programs. The distribution of household access is therefore broadly comparable across the two groups.

In general, those who use neither program seem to have better indicators of BMI and less morbidity, especially among women (Table 1). This could be indicative of selection effects, such that those with worse indicators might select into the programs with others self-selecting out. This is not surprising since the MGNREGA pays minimum wages for manual unskilled work and the PDS provides relatively poorer quality grain - both tend to select in the relatively poor (Liu and Barrett, 2013), who are also likely to have poorer nutrition and health outcomes. For the analysis, we consider those accessing both programs as the 'treated' group and those not accessing both programs as the control group. The latter includes those accessing only one of the two programs as well as those not accessing either of these programs.

Table 1: MGNREGA \& PDS Participation and Health status of the IHDS Sample, 2011-12

\begin{tabular}{|c|c|c|c|c|c|}
\hline & $\begin{array}{r}\text { Mean } \\
\text { BAZ/BMI }\end{array}$ & $\begin{array}{r}\text { Proportion } \\
\text { reporting } \\
\text { short term } \\
\text { morbidity }\end{array}$ & $\begin{array}{l}\text { Average } \\
\text { days of } \\
\text { morbidity }\end{array}$ & $\begin{array}{l}\text { Number of } \\
\text { observa- } \\
\text { tions }\end{array}$ & $\begin{array}{l}\text { Percentage } \\
\text { of total }\end{array}$ \\
\hline \multicolumn{6}{|l|}{ Children } \\
\hline Both & -1.156 & 0.24 & 1.392 & 1255 & 16.29 \\
\hline Only PDS & -0.952 & 0.19 & 0.939 & 2680 & 34.79 \\
\hline $\begin{array}{l}\text { Only } \\
\text { MGNREGA }\end{array}$ & -1.195 & 0.24 & 1.332 & 674 & 8.75 \\
\hline Neither & -0.976 & 0.23 & 1.247 & 3095 & 40.17 \\
\hline Either + Neither & -0.989 & 0.21 & 1.128 & 6449 & 83.71 \\
\hline All & -1.016 & 0.22 & 1.171 & 7704 & \\
\hline \multicolumn{6}{|l|}{ Women } \\
\hline Both & 21.014 & 0.25 & 1.637 & 2764 & 16.77 \\
\hline Only PDS & 21.725 & 0.2 & 1.507 & 6900 & 41.86 \\
\hline $\begin{array}{l}\text { Only } \\
\text { MGNREGA }\end{array}$ & 20.5 & 0.29 & 2.253 & 996 & 6.04 \\
\hline Neither & 22.072 & 0.23 & 1.657 & 5822 & 35.32 \\
\hline Either + Neither & 21.783 & 0.22 & 1.625 & 13718 & 83.23 \\
\hline All & 21.655 & 0.22 & 1.627 & 16482 & \\
\hline
\end{tabular}

Source: Computed by authors based on IHDS-II 
Table 2: Baseline and Post- treatment health and nutrition status of eligible women and children.

\begin{tabular}{|c|c|c|c|c|}
\hline & \multicolumn{2}{|c|}{ 2004-05 } & \multicolumn{2}{|c|}{ 2011-12 } \\
\hline & $\begin{array}{r}\text { Treated (Both } \\
\text { PDS + NREGA) }\end{array}$ & $\begin{array}{r}\text { Control } \\
\text { (Either + } \\
\text { Neither) } \\
\end{array}$ & $\begin{array}{r}\text { Treated (Both } \\
\text { PDS + NREGA) }\end{array}$ & $\begin{array}{r}\text { Control } \\
\text { (Either + } \\
\text { Neither) } \\
\end{array}$ \\
\hline Children BAZ & -0.35 & -0.16 & -1.16 & -0.99 \\
\hline $\begin{array}{l}\text { Average days of } \\
\text { morbidity - } \\
\text { Children }\end{array}$ & $2.06^{\#}$ & $2.22^{\#}$ & 1.39 & 1.13 \\
\hline Women BMI & 20.24 & 20.74 & 21.01 & 21.78 \\
\hline $\begin{array}{l}\text { Average days of } \\
\text { morbidity - } \\
\text { Women }\end{array}$ & 1.32 & 1.06 & $1.64^{\#}$ & $1.63^{\#}$ \\
\hline
\end{tabular}

Source: Computed by authors based on IHDS- I \& II

Note: \# Difference is not statistically significant. We use baseline and post somewhat loosely since as explained, the PDS was in place in both years and although the MGNREGA was implemented in 2007, other workfare programs were in place although with marginal reach.

\subsection{Empirical Strategy}

We employ two different approaches to answer the questions at hand. Our preferred approach is a semi-parametric difference-in-differences approach (SDID) proposed by Abadie (2005) to identify Average Treatment Effect on the Treated (ATT). Given that those who use both the MGNREGA and PDS could be systematically different from those who use neither or one of the programs based on observable characteristics, estimates that ignore this are likely to be biased. This approach addresses the imbalance in characteristics between the treated and comparison groups. The additional advantage that this approach has over a traditional difference-in-differences (DID) approach is that this can address violations of the parallel trends assumption, so crucial for DID, that in the absence of treatment the outcome variable would have followed the same trend in the treated and untreated groups (Houngbedji, 2015). Accordingly, SDID is given by

$$
E\left(\frac{\Delta y}{P(d=1)} \times \frac{d-\pi\left(X_{b}\right)}{1-\pi\left(X_{b}\right)}\right)
$$

where $\Delta y$ is the change in outcome over the two periods, $\mathrm{d}$ is the treatments status, $X_{b}$ is the vector of baseline characteristics that drive selection into treatment, $\pi\left(X_{b}\right)$ 
is the propensity to get treated. The estimator is a weighted average of the difference of trend $(\Delta y)$ across treatment groups. It reweights the trend for untreated participants based on their propensity score $\frac{\pi\left(X_{b}\right)}{1-\pi\left(X_{b}\right)}$ that derives from baseline characteristics. The term (1) is an unbiased estimate of ATT if the following assumptions below hold.

$$
\begin{gathered}
E\left(y_{0 t}-y_{0 b} \mid d=1 ; x_{b}\right)=E\left(y_{0 t}-y_{0 b} \mid d=0 ; x_{b}\right) \\
P(d=1)>0 \text { and } \pi\left(x_{b}\right)<1 \text { (3) }
\end{gathered}
$$

The assumptions (Equations 2 and 3) are: given the baseline characteristics, the treated and control units that share these characteristics would have the same treatment effects. The propensity score for the treated is a subset of the support of the propensity score for the untreated. We believe this approach is relevant given the limitation with our data that we cannot explicitly test for parallel trends. Further, in the case of the MGNREGA and PDS, both pro-poor programs, selection characteristics could also affect the dynamic of the outcome and hence the SDID approach is more appropriate in this context.

SDID estimates are however sensitive to the type of approximation used for the propensity score and we therefore use both the simple linear probability model and a series logit estimator (Hirano, et al., 2003) to estimate propensity score rather than a simple polynomial series or orders of polynomial approximation. ${ }^{13}$ In all the models, we estimate propensity score using the same set of covariates relating to the individual's baseline (2004-05) characteristics.

In addition to the semi-parametric DID we also implement a Difference-inDifferences to a matched subsample, where the matching is based on the propensity score. We perform the PSM analysis using the 2005 sample and keep only the matched households from 2005 and merge them with the panel so that the DID analysis is done only for the matched households. ${ }^{14}$ In these models, we cluster errors at the household level, given that program participation is at the household level and given that our sample comprises multiple respondents from the same household.

\footnotetext{
${ }^{13}$ While we present the estimates with both LPM and SLE estimation methods with polynomial order 1 , our results are also robust to higher orders of the polynomial used in the propensity score estimation. These results are not reported here but are available on request.

${ }^{14}$ This is different from a DID model that weights the observations using propensity score.
} 


\section{Results and Discussion}

\subsection{SDID analysis}

For the SDID analysis, we use the following variables from the baseline survey for the estimation of the propensity scores: income per-capita (excluding the income received from SGRY/FFW) and its square, land size, education of the household head (for children sample)/occupation (for women), adult sex ratio, number of married females in the household (proxy for family structure), social group, household's participation in SGRY in 2005, household's participation in PDS in 2005; age of household head, years of education (for women), an index for assets for measuring household possessions and housing quality (constructed by the IHDS), nearest town distance (categorical variable). While the MGNREGA was first implemented in 2007, it subsumed two other predecessors - the Sampoorna Grameen Rozgar Yojana (SGRY) and the Food for Work program (FFW). We consider households' participation in these programs from the IHDS data from 2005 as a predictor for whether they are likely to participate in the MGNREGA and hence influence their propensity to be a treated household in 2011-12. ${ }^{15}$

In addition, there are some states where the MGNREGA was implemented well and it is likely that households residing in these states are more likely to participate in MGNREGA. Following Imbert and Papp (2015)'s classification of states performing well on the implementation of MGNREGA, ${ }^{16}$ we include a variable on whether the individual resides in one of these 'star states' or in West Bengal, which, the IHDS data show, has also been performing well on the implementation of MGNREGA. About 37 percent of the women sample and 39 percent of children's sample reside in these eight states. Moreover, there are a few states where the access to PDS is universal or near universal and not limited to the poor. Residing in these states could increase the propensity of a household to participate in PDS. Based on Khera (2011a) there are four states where PDS is universal or near universal. ${ }^{17}$ It turns out these states are a subset of the 'star states'. Hence, when we control for whether the individual resides in one of these 'star states', we are inherently accounting for the

\footnotetext{
15 There are only 7 observations in the children sample and 18 observations in the women sample whose households have participated in SGRY and PDS in 2004-05.

${ }^{16}$ These are a set of seven states, namely, Andhra Pradesh, Chhattisgarh, Himachal Pradesh, Madhya Pradesh, Rajasthan, Uttarakhand, and Tamil Nadu denoted as 'star states' in Imbert and Papp (2015).

17 These are Tamil Nadu, Himachal Pradesh, Andhra Pradesh, and Chhattisgarh.
} 
state-specific effects of residing either in those states with universal/near-universal PDS or in those that implement the MGNREGA well. ${ }^{18}$

We present SDID estimates of Average Treatment Effect among the Treated (ATT) in Table 3, where the propensity score is based on a Linear Probability Model (LPM) and then a Series Logit Estimator (SLE). The number of observations used in the estimation with LPM is smaller than the full sample since observations with propensity score greater than 1 or less than zero are dropped while estimating ATT using the LPM method. On the other hand, the advantage with the Series Logit Estimator (SLE) is that it uses a logistic function to estimate the propensity score and hence all the observations in the sample can be used for the analysis.

For women, participation in the MGNREGA and PDS leads to lower shortterm morbidity by 0.26 to 0.28 days, relative to not participating in both programs. This effect is equal to $25 \%$ of the comparison group average during the baseline. There is however no impact on women's BMI. For children, we find the opposite results. While there is no evidence for any impact of the participation in the MGNREGA and PDS on children's morbidity, children from the participating households experience an increase in their BMI-for-Age Z-scores (BAZ) as per both the LPM and SLE estimations, by 0.12 to 0.16 points, although the LPM results are statistically weaker. Considering that the baseline BAZ for children in the comparison group is -0.16 (Table 2), this essentially suggests that children's BMI deficits are virtually fully erased.

Table 3: Average Treatment Effects from semi-parametric DiD

\begin{tabular}{|c|c|c|c|c|}
\hline & \multicolumn{2}{|c|}{ BMI / BAZ } & \multicolumn{2}{|c|}{ Morbidity } \\
\hline & LPM & Series Logit & LPM & Series Logit \\
\hline \multicolumn{5}{|l|}{ Women } \\
\hline ATT & -0.053 & 0.007 & $-0.257^{* *}$ & $-0.278^{* *}$ \\
\hline Constant & $(0.072)$ & $(0.077)$ & $(0.119)$ & $(0.128)$ \\
\hline Observations & 14676 & 16482 & 14676 & 16482 \\
\hline \multicolumn{5}{|l|}{ Children } \\
\hline ATT & $0.127^{*}$ & $0.157^{* *}$ & 0.246 & 0.250 \\
\hline Constant & $(0.069)$ & $(0.074)$ & $(0.160)$ & $(0.167)$ \\
\hline Observations & 6894 & 7703 & 6894 & 7703 \\
\hline
\end{tabular}

\footnotetext{
18 There are a few observations where information on some of these variables is missing. For these, we incorporate missing value dummies. The details have been provided in the Appendix.
} 
The SDID estimates above were obtained using the polynomial order 1. Our results remain when we estimate the ATT with polynomial orders 2,3 , and $4 .^{19}$

\section{What drives the treatment effects?}

One of the advantages of the SDID approach is that it allows us to assess whether the treatment effect varies with baseline characteristics associated with the individual (Abadie, 2005). We are therefore able to assess whether the ATT varies with respect to the following covariates: income per-capita (excluding income from SGRY), whether the individual is resident in either one of the states with well-performing MGNREGA or in states with (near-) universal PDS, distance of the village from the nearest town (categorical variable), whether the individual's village has health facilities; in addition, for the the analysis of children, we also consider the gender of the child and the distance of the village from the nearest anganwadi (government-run childcare) centre (Table 4).

Women residing in states with well-performing MGNREGA or with (near-) universal PDS experience significant improvements in their BMI by participating in these programs such that the ATT on BMI for women in these states is higher by between 0.67 and 0.77 as compared to the ATT on women participants from other states. This represents a $3.77 \%$ increase relative to the baseline BMI for women in the comparison group in these well-performing states. There is a legitimate concern that increases in BMI are not necessarily a good thing if those experiencing these increases are already those with high BMI, in the overweight/obesity spectrum. We examine this issue in Section 5.

In addition, there is a small but statistically significant 'penalty' on the ATT on BMI for participants from richer households relative to the ATT for relatively poorer households, indicating a pro-poor bias in the effect. To the extent that overweight and obesity in the sample is higher among the richer/non-poor households, the 'penalty' here is in fact a desirable thing, indicating that the impacts

\footnotetext{
${ }^{19}$ These results are available on request.
} 
of these programs are more muted for those who are more likely to be overweight or obese. $^{20}$

On the other hand, there is some evidence suggesting that both women and children (Table 4) who are accessing these programs and are living in villages which are sufficiently farther away from towns (more than $30 \mathrm{kms}$.) are more vulnerable to short-term morbidity than participants residing in villages that are closer to a town (less than $5 \mathrm{kms}$.). This is unsurprising since benefits to health and nutrition are predicated on the availability of good quality of healthcare. ${ }^{21}$

\footnotetext{
${ }^{20}$ We find that the correlation between BMI and income is positive although small, 0.1624 .

${ }^{21}$ We note that morbidity is a self-reported variable in our data, and thus could be higher among more educated households (or located in richer states) due to greater awareness. However, we find no such correlation in our data (using state of residence as a proxy).
} 
Table 4: Covariates ATT for Women and Children

\begin{tabular}{|c|c|c|c|c|c|c|c|c|}
\hline \multirow{3}{*}{ ATT } & \multicolumn{4}{|c|}{ Women } & \multicolumn{4}{|c|}{ Children } \\
\hline & \multicolumn{2}{|c|}{ BMI } & \multicolumn{2}{|c|}{ Morbidity } & \multicolumn{2}{|c|}{ BMI } & \multicolumn{2}{|c|}{ Morbidity } \\
\hline & LPM & Series Logit & LPM & Series Logit & LPM & Series Logit & LPM & Series Logit \\
\hline $\begin{array}{l}\text { Total income per-capita minus income } \\
\text { from SGRY per-capita }\end{array}$ & $\begin{array}{l}-0.00003^{* * * *} \\
(0.000007)\end{array}$ & $\begin{array}{l}-0.00002^{* *} \\
(0.000012)\end{array}$ & $\begin{array}{c}0.00001 \\
(0.000014)\end{array}$ & $\begin{array}{c}0.00001 \\
(0.000017)\end{array}$ & $\begin{array}{c}-0.00001 \\
(0.000005)\end{array}$ & $\begin{array}{l}-0.00001^{\text {**** }} \\
(0.000004)\end{array}$ & $\begin{array}{c}0 \\
(0.000007)\end{array}$ & $\begin{array}{c}0 \\
(0.000007)\end{array}$ \\
\hline \multicolumn{9}{|c|}{ Whether resident in either one of the states with well-performing MGNREGA or in states with universal PDS ${ }^{\text {a }}$ (Base: Not resident) } \\
\hline 'Star-state+’’ resident & $\begin{array}{l}0.76659^{* * *} \\
(0.148947)\end{array}$ & $\begin{array}{l}0.67469^{* * *} \\
(0.158681)\end{array}$ & $\begin{array}{c}-0.0812 \\
(0.251302)\end{array}$ & $\begin{array}{l}-0.23276 \\
(0.270075)\end{array}$ & $\begin{array}{c}-0.20726 \\
(0.141693)\end{array}$ & $\begin{array}{c}-0.0095 \\
(0.151905)\end{array}$ & $\begin{array}{l}-0.37738 \\
(0.33223)\end{array}$ & $\begin{array}{c}-0.25599 \\
(0.348595)\end{array}$ \\
\hline \multicolumn{9}{|c|}{ Whether the village has health facilities (Base: No) ${ }^{b}$} \\
\hline The village has health facility & $\begin{array}{c}-0.21088 \\
(0.148152)\end{array}$ & $\begin{array}{c}-0.12976 \\
(0.158314)\end{array}$ & $\begin{array}{c}-0.03829 \\
(0.240484)\end{array}$ & $\begin{array}{l}-0.01855 \\
(0.2576)\end{array}$ & $\begin{array}{c}0.1718 \\
(0.15051)\end{array}$ & $\begin{array}{c}0.0987 \\
(0.164412)\end{array}$ & $\begin{array}{c}0.35819 \\
(0.334274)\end{array}$ & $\begin{array}{c}0.24735 \\
(0.34968)\end{array}$ \\
\hline \multicolumn{9}{|c|}{ Distance of the village from the nearest town (Base: distance is $"<=5 \mathrm{~km} "$ ) } \\
\hline Between 6 and $10 \mathrm{~km}$ & $\begin{array}{c}0.07256 \\
(0.217658)\end{array}$ & $\begin{array}{c}0.10427 \\
(0.233961)\end{array}$ & $\begin{array}{c}0.15634 \\
(0.356174)\end{array}$ & $\begin{array}{c}0.2054 \\
(0.385397)\end{array}$ & $\begin{array}{l}0.42878^{* *} \\
(0.210953)\end{array}$ & $\begin{array}{c}0.36231 \\
(0.229684)\end{array}$ & $\begin{array}{c}-0.22039 \\
(0.451184)\end{array}$ & $\begin{array}{l}-0.18678 \\
(0.46645)\end{array}$ \\
\hline Between 11 and $20 \mathrm{~km}$ & $\begin{array}{c}0.22377 \\
(0.204846)\end{array}$ & $\begin{array}{c}0.24739 \\
(0.220284)\end{array}$ & $\begin{array}{l}-0.15597 \\
(0.36219)\end{array}$ & $\begin{array}{c}-0.09298 \\
(0.387696)\end{array}$ & $\begin{array}{c}0.1236 \\
(0.196721)\end{array}$ & $\begin{array}{c}0.04417 \\
(0.213622)\end{array}$ & $\begin{array}{c}-0.60943 \\
(0.427036)\end{array}$ & $\begin{array}{c}-0.57268 \\
(0.442257)\end{array}$ \\
\hline Between 21 and $30 \mathrm{~km}$ & $\begin{array}{c}0.12079 \\
(0.27057)\end{array}$ & $\begin{array}{c}0.23578 \\
(0.293782)\end{array}$ & $\begin{array}{c}0.41373 \\
(0.420151)\end{array}$ & $\begin{array}{c}0.48504 \\
(0.450716)\end{array}$ & $\begin{array}{c}-0.24119 \\
(0.258553)\end{array}$ & $\begin{array}{c}-0.16364 \\
(0.289447)\end{array}$ & $\begin{array}{c}-0.67822 \\
(0.616745)\end{array}$ & $\begin{array}{c}-0.51809 \\
(0.637823)\end{array}$ \\
\hline Greater than $>30 \mathrm{~km}$ & $\begin{array}{c}0.13445 \\
(0.299821)\end{array}$ & $\begin{array}{c}0.22157 \\
(0.316536)\end{array}$ & $\begin{array}{c}0.97376^{*} \\
(0.576277)\end{array}$ & $\begin{array}{c}1.01255^{*} \\
(0.614272)\end{array}$ & $\begin{array}{c}0.45674 \\
(0.28153)\end{array}$ & $\begin{array}{c}0.29787 \\
(0.309312)\end{array}$ & $\begin{array}{c}1.49753^{* *} \\
(0.716993)\end{array}$ & $\begin{array}{c}1.37831^{*} \\
(0.732587)\end{array}$ \\
\hline $\begin{array}{l}\text { Distance of the nearest anganwadi from } \\
\text { the village (in kms) }\end{array}$ & & & & & $\begin{array}{c}-0.00811 \\
(0.080414)\end{array}$ & $\begin{array}{c}-0.02819 \\
(0.087892)\end{array}$ & $\begin{array}{c}-0.0398 \\
(0.233533)\end{array}$ & $\begin{array}{c}-0.04567 \\
(0.232186)\end{array}$ \\
\hline $\begin{array}{l}\text { No response for Distance of the nearest } \\
\text { anganwadi from the village }(=1)\end{array}$ & & & & & $\begin{array}{c}0.18476 \\
(0.416676)\end{array}$ & $\begin{array}{c}0.04848 \\
(0.439534)\end{array}$ & $\begin{array}{l}-1.46194 \\
(0.906062)\end{array}$ & $\begin{array}{l}-1.64337^{*} \\
(0.924232)\end{array}$ \\
\hline Female $(=1)$ (Base: Male) & & & & & $\begin{array}{c}0.02755 \\
(0.14782)\end{array}$ & $\begin{array}{c}0.12264 \\
(0.162078)\end{array}$ & $\begin{array}{c}-0.37426 \\
(0.322263)\end{array}$ & $\begin{array}{c}-0.36551 \\
(0.336655)\end{array}$ \\
\hline Constant & $\begin{array}{l}-0.43289^{* *} \\
(0.20664)\end{array}$ & $\begin{array}{l}-0.42167^{*} \\
(0.226438)\end{array}$ & $\begin{array}{c}-0.36753 \\
(0.362226) \\
\end{array}$ & $\begin{array}{l}-0.33629 \\
(0.4015) \\
\end{array}$ & $\begin{array}{c}0.0344 \\
(0.203654) \\
\end{array}$ & $\begin{array}{c}-0.0005 \\
(0.218752) \\
\end{array}$ & $\begin{array}{c}0.79521^{*} \\
(0.453146) \\
\end{array}$ & $\begin{array}{r}0.77737 \\
(0.476428) \\
\end{array}$ \\
\hline Observations & 14676 & 16482 & 14676 & 16482 & 6894 & 7703 & 6894 & 770317 \\
\hline
\end{tabular}


Notes to the table:

$* \mathrm{p}<0.10, \quad * * \mathrm{p}<0.05, * * * \mathrm{p}<0.01$

Figures in the parenthesis are standard errors.

a'These include the union of a group of seven 'Star states' that are well-performing on MGNREGA, namely Himachal Pradesh, Uttarakhand, Rajasthan, Chhattisgarh, Andhra Pradesh (including Telangana), Tamil Nadu, Madhya Pradesh as per Imbert and Papp (2015) and the group of states where PDS is universal or near-universal, namely Andhra Pradesh (including Telangana), Tamil Nadu, Himachal Pradesh and Chhattisgarh as per Khera (2011); in addition, we have West Bengal which is shown in the data to have similar penetration of these programs as these states.

${ }^{b}$ Health facilities at the village level: Those living in villages that have access to at least one of the following: Health Sub-center, Govt. Dispensary, Primary Health Center, Community Health Center, District Hospital, Government Maternity Center, Private Clinic / Private Doctor - Trained, Private Hospital / Nursing Home, or Any Other Govt. Medical Facility.

\subsection{DID on matched sample}

As an alternative to the SDID, we estimate a traditional regression-based difference-in-difference (DID) model using a sample matched on the propensity scores. We estimate the propensity score using characteristics from the baseline data similar to those we used for the SDID. ${ }^{22}$ These include non-SGRY income per-capita and its square, occupation, adult sex ratio, number of married females in the household (proxy for household structure), whether the individual lives in a 'star state' or a (near-) universal PDS state (as defined earlier). In addition to these, we also use the variables of land size and social group for estimating the propensity score for the children's sample. Only those individuals that are matched from the PSM analysis are then merged with the panel so that the DID is conducted on only matched individuals. $^{23}$

We estimate the following DID model:

$$
y_{i h t}=\alpha_{i}+\beta T_{h} t+\delta T_{h}+\gamma t+\rho_{1} X_{i t}+\rho_{2} X_{h t}+\rho_{3} X_{v t}+\varepsilon_{i h t}
$$

where the subscripts ' $i$ ', ' $h$ ', ' $v$ ' and ' $t$ ' denote the individual, household, village and time respectively. The variable ' $T_{h}$ ' denotes the treatment dummy of whether the household accessed PDS and MGNREGA in 2012 such that $T_{h}=1$ for households

\footnotetext{
${ }^{22}$ We use the STATA command 'pscore' to estimate the propensity scores.

${ }^{23}$ About 45 observations from the women sample and 161 observations from the children's sample were dropped from the baseline data as a result of the PSM exercise. The details of the PSM matching are available in the Appendix.
} 
that accessed both these programs and $T_{h}=0$ for other households; $X$ denote a set of controls, which include the following:

Age, social group (i.e. caste and religion), occupation, individual's education (for the women's sample) / household head's education (for the children's sample), household size, dependency ratio, age of household head, adult sex ratio, whether household headed by female, number of married females in the household, nonNREGA income per-capita, assets, land size, access to health facilities, access to toilet, piped water, income from other government programs, access to other foodbased welfare schemes like Annapurna, and whether the household belongs to star states. In addition, we have village-level control variables such as village's distance from surfaced road, nearest town, number of health facilities in the village. Moreover, since the outcome variables exhibit strong seasonality, we control for the quarter of the year in which the interview was administered. Further, since the treatment is at the level of the household, the standard errors have been clustered at the household level. We estimate both an Ordinary Least Squares (OLS) estimation as well as an individual fixed effects (FE) estimation, using the panel structure of the data. ${ }^{24}$ Table 5 contains the results for women and Table 6 for children (see Supplementary Materials for detailed results).

When we control for individual specific fixed effects, the DID estimate suggests that participation in both programs lowers short-term morbidity among women in participant households. Moreover, we also observe that participation leads to lower BMI among women in participant households. This latter result is not too surprising, given the physical hardship involved in working as part of the MGNREGA and delay in wage payments, as well as intra-household distribution issues governing the distribution of resources. If the physical effort of MGNREGA work impacts BMI adversely, then presumably that effect should only come about if the woman herself is participating in the program as opposed to household level participation. In order to verify the impact of the woman's participation on her health, we control for an individual participation dummy in MGNREGA and conduct the matched DID analysis for both the outcomes, BMI and short-term morbidity. Table 5 below shows that once the individual participation in MGNREGA is controlled for, the DID coefficient for BMI is not significant, whereas the individual participation dummy is

${ }^{24}$ For the OLS estimation, the model we estimate is without the individual-specific fixed effects, $\alpha_{i}$. 
negative and significant. This supports our hypothesis that the negative impact is attributable entirely to the woman's own participation in the MGNREGA. This points of course to the need for wages to compensate work effort adequately, timely payments of these wages and effort-saving implements for work.

Table 5: Impacts on women using the matched DID approach

\begin{tabular}{|c|c|c|c|c|c|c|}
\hline \multirow{3}{*}{ Model } & \multicolumn{3}{|c|}{ BMI } & \multicolumn{3}{|c|}{ Morbidity } \\
\hline & OLS & F.E. & $\begin{array}{l}\text { F.E. } \\
\text { Control for } \\
\text { participatio } \\
\text { n }\end{array}$ & OLS & F.E. & $\begin{array}{c}\text { F.E. } \\
\text { Control for } \\
\text { participatio } \\
\text { n }\end{array}$ \\
\hline & (1) & (2) & (3) & (4) & (5) & (6) \\
\hline \multirow{2}{*}{ DID Estimate } & -0.043 & $-0.168^{* *}$ & -0.040 & $-0.207^{*}$ & $-0.272^{* *}$ & $-0.299^{* *}$ \\
\hline & $(0.0712)$ & $(0.071)$ & $(0.088)$ & (0.116) & (0.119) & (0. 146) \\
\hline \multirow{2}{*}{$\begin{array}{l}\text { MGNREGA } \\
\text { participant } \\
(=1)\end{array}$} & & & $-0.252 * *$ & & & 0.053 \\
\hline & & & $(0.099)$ & & & $(0.173)$ \\
\hline Observations & 32874 & 32874 & 32874 & 32874 & 32874 & 32874 \\
\hline
\end{tabular}

Note: Standard error in the parenthesis and are clustered at the household. * $\mathrm{p}<0.10, \quad * * \mathrm{p}<0.05, * * *$ $\mathrm{p}<0.01$. O.L.S. denotes Ordinary Least Squares estimate. F.E. denotes estimates with individual fixed effects.

For children, we get results that are not entirely consistent with the SDID approach. Participation in both programs impacts neither the children's BAZ nor their shortterm morbidity consistently across model specifications (see columns (1) and (2) in Table 6 below).

To the extent that the SDID analysis shows that children's BAZ is improving from belonging to a treated household, it is of interest to know if the gender of their household's adult participant in the treatment matters in impacting children's health. While it is not possible to assess the intra-household distribution of grains from the PDS, we can look at instances where either only males or only females from the household have participated in MGNREGA and assess the differential impact on children's health. This addresses an established view that benefits accruing to women are more likely to be channeled to food consumption and health, especially for children (Thomas, 1990; Alderman et al., 1997, for example).

To ascertain this, we analyze subsamples separately, restricting the treatment group to children in households where only women work on the MGNREGA, then to children in households where only the men work on the MGNREGA and then those in households where both men and women work. Out of 15086 observations for 
children that matched, gender-wise household participation in the MGNREGA was available for 15044 observations and we use these for the subsample analysis. For this set of regressions we also control for the intensity of participation, so that we partial out the effect of working more versus less, focusing instead on the channel through which the incomes accrue to the household. Table 6 indicates that only when both men and women work, children in treated households experience an improvement in their BAZ. In contrast when only men work, there is weak evidence that their morbidity increases. Households with only women participation in MGNREGA do not seem to have either adverse or beneficial impacts. This is perhaps indicative of interesting intra-household effects, spurred for example by gender differences in the way the negative impacts of MGNREGA on the participants' BMI is compensated for (or not) and transferred to their children (or not). Data limitations prevent us from exploring this further. 
Table 6 : Impacts on children using the matched DID approach - control group same for full sample and sub samples

Restricting treated households to those PDS accessing households where

\begin{tabular}{|c|c|c|c|c|c|c|}
\hline Full sample & $\begin{array}{l}\text { only women } \\
\text { participate in } \\
\text { NREG }\end{array}$ & $\begin{array}{l}\text { only men } \\
\text { participate in } \\
\text { NREG }\end{array}$ & $\begin{array}{l}\text { both women and } \\
\text { men participate } \\
\text { in NREG }\end{array}$ & $\begin{array}{l}\text { Only women } \\
\text { participate in } \\
\text { NREG. }\end{array}$ & $\begin{array}{l}\text { Only men } \\
\text { participate in } \\
\text { NREG. }\end{array}$ & $\begin{array}{l}\text { Both women and } \\
\text { men participate in } \\
\text { NREG. }\end{array}$ \\
\hline
\end{tabular}

\begin{tabular}{|c|c|c|c|c|c|c|c|c|}
\hline & OLS & F.E. & F.E. & F.E. & F.E. & F.E. & F.E. & F.E. \\
\hline & (1) & (2) & $(3)^{\#}$ & $(4)^{\#}$ & $(5)^{\#}$ & $(6)^{\#}$ & $(7)^{\#}$ & $(8)^{\#}$ \\
\hline DID Estimate for & 0.083 & 0.097 & -0.081 & 0.089 & $0.208^{*}$ & -0.074 & 0.087 & $0.244^{*}$ \\
\hline BAZ & $(0.071)$ & $(0.071)$ & $(0.124)$ & $(0.109)$ & $(0.118)$ & $(0.133)$ & $(0.113)$ & $(0.129)$ \\
\hline $\begin{array}{l}\text { DID Estimate for } \\
\text { Morbidity }\end{array}$ & $\begin{array}{l}0.437^{* * * *} \\
(0.163)\end{array}$ & $\begin{array}{l}0.248 \\
(0.165)\end{array}$ & $\begin{array}{c}0.061 \\
(0.290)\end{array}$ & $\begin{array}{l}0.513 * \\
(0.264)\end{array}$ & $\begin{array}{l}0.112 \\
(0.259\end{array}$ & $\begin{array}{c}0.043 \\
(0.325)\end{array}$ & $\begin{array}{l}0.517 * \\
(0.272)\end{array}$ & $\begin{array}{c}0.163 \\
(0.301)\end{array}$ \\
\hline $\begin{array}{l}\text { Coefficient on No. } \\
\text { of days of } \\
\text { participation of } \\
\text { household in NREG } \\
\text { for BAZ outcome }\end{array}$ & & & & & & $\begin{array}{l}-0.0001 \\
(0.001)\end{array}$ & $\begin{array}{c}0.00009 \\
(0.001)\end{array}$ & $\begin{array}{l}-0.0006 \\
(0.0010)\end{array}$ \\
\hline $\begin{array}{l}\text { Coefficient on No. } \\
\text { of days of } \\
\text { participation of } \\
\text { household in NREG } \\
\text { for morbidity } \\
\text { outcome }\end{array}$ & & & & & & $\begin{array}{l}0.0004 \\
(0.003)\end{array}$ & $\begin{array}{l}-0.0001 \\
(0.002)\end{array}$ & $\begin{array}{l}-0.0009 \\
(0.002)\end{array}$ \\
\hline Observations & 15086 & 15086 & 13258 & 13426 & 13388 & 13258 & 13426 & 13388 \\
\hline
\end{tabular}

Note: Standard errors are in the parenthesis and are clustered at the household. ${ }^{*} \mathrm{p}<0.10,{ }^{* *} \mathrm{p}<0.05, * * * \mathrm{p}<0.01$. These are estimates with individual fixed effects. ${ }^{\#}$ For estimations in columns (3) to (8), the control group is the same as that for the full sample. 


\section{Robustness Checks}

As a robustness exercise for the women sample, we performed all of the above analysis on two subsamples to see if the results continue to hold. They are: (1) subsample residing in the eight well-performing states, constituting about 37 percent of the entire sample and (2) subsample with their BMI values less than 25 in both the years (the threshold for being classified as overweight), constituting about 77 percent of the entire sample.

For the subsample residing in the eight well-performing states, the results for women show that the impact of treatment on lowering morbidity continues to hold, with a magnitude in the range of 0.29 to 0.31 days. This result aligns with that for the entire sample as per the SDID analysis although only at 10 percent significance, whereas we had not found significant impact using matched DID analysis. With respect to the BMI, we find treatment to improve BMI in the LPM specification of SDID analysis but only at 10 percent significance, whereas the matched DID analysis shows a positive impact on BMI at 5 percent significance. The magnitude of improvement is in the range of 0.16 to 0.23 points. Using the baseline summary stats data for the control group, this is shown to be about $1.2 \%$ higher than control group's baseline average BMI.

For the sample of women with BMI values less than 25, we see that the only statistically significant result for overall ATT is in case of morbidity with the matched DID analysis where morbidity is lower by about 0.27 days but only at 10 percent significance. Moreover, when we consider the covariate-specific ATT for this subsample, we see that the ATT on BMI for those residing in the eight wellperforming states is highly significant and is higher by about 0.48 to 0.53 points than the ATT for those outside these states, echoing the results we found for the entire sample. This is a positive result since this suggests that those who are undernourished as per the BMI stand to gain from participation. Due to the limited number of observations of women who are overweight or obese we are unable to estimate the impacts for this sub-group.

With respect to the children's sample, we similarly check for robustness focussing on the sub-sample of those residing in the eight well-performing states, constituting about 39 percent of the entire sample. However, we do not find 
statistically significant results for any of the models with either of the two outcome variables. $^{25}$ This suggests that the results for children are driven by the other states.

Table 7: Impacts for the well-performing 'Star'+ West Bengal states

\begin{tabular}{lcccccc}
\hline & \multicolumn{3}{c}{ Morbidity } & \multicolumn{3}{c}{ BMI / BAZ } \\
\hline LPM & $\begin{array}{c}\text { Series } \\
\text { Logit }\end{array}$ & $\begin{array}{c}\text { Matched } \\
\text { DID F.E. }\end{array}$ & LPM & $\begin{array}{c}\text { Series } \\
\text { Logit }\end{array}$ & $\begin{array}{c}\text { Matched } \\
\text { DIDF.E. }\end{array}$ \\
\hline Women & & & & & & \\
\hline ATT & $-0.289^{*}$ & $-0.314^{*}$ & -0.255 & $0.163^{*}$ & 0.147 & 0.098 \\
$(0.156)$ & $(0.161)$ & $(0.178)$ & $(0.096)$ & $\begin{array}{c}0.228^{* *} \\
6)\end{array}$ & $(0.115)$ \\
\hline $\begin{array}{l}\text { Observation } \\
\mathrm{s}\end{array}$ & 5940 & 6070 & 12054 & 5940 & 6070 & 12054 \\
\hline
\end{tabular}

\section{Children}

$\begin{array}{ccccccc} & 0.169 & 0.171 & 0.229 & 0.071 & 0.076 & 0.075 \\ \text { ATT } & (0.204) & (0.206) & (0.215) & (0.090) & (0.091)\end{array}$

\begin{tabular}{lllllll}
$\begin{array}{l}\text { Observation } \\
\mathrm{s}\end{array}$ & 2915 & 2976 & 5842 & 2915 & 2976 & 5842 \\
\hline
\end{tabular}

Note: Standard errors are in the parenthesis. F.E. denotes individual fixed effects. For the matched DID models with individual fixed effects, standard errors are clustered at the household. ${ }^{*} \mathrm{p}<0.10, * * \mathrm{p}<0.05, * * * \mathrm{p}<0.01$.

In addition to these, we also estimated models to address potential measurement error in the age of the individual. About 2 percent ( 0.31 percent) of the sample used for the women analysis (children's analysis) has incongruous data on the 'age' variable such that the individual's age in 2012 is lower than or same as that in 2005. The IHDS website suggests that when such discordance exists for demographic variables ("for example a respondent's age, sex, religion or caste" ${ }^{26}$ ), the data from the 2011-12 round is to be used. Given this, in addition to using the 'age' variable as provided by the IHDS, we also perform the following robustness checks using the following three alternate scenarios: first, we consider the age in 2004-05 to be 8 years lower than that in 2011-12; second, we take age in 2004-05 to be 6 years lower than

\footnotetext{
${ }^{25}$ The detailed results of these robustness exercises for both the women and children's analysis are available on request.

26 Please refer to this "Frequently Asked Question" on the IHDS website: https://ihds.umd.edu/faq/when-there-difference-demographic-indicator-data-should-not-changebetween-ihds-i-and-ihds-ii [accessed on February 19, 2019] which states the following: "Use IHDS II which has been more recently cleaned and updated; in addition, we believe our second round of data benefits from our experience with the first in terms of procedures and supervision so IHDS II data is preferred".
} 
that in 2011-12 and in the third alternate scenario, we drop from the analyses those observations which have age in 2011-12 to be lower than or to be same as age in 2004-05. In all these three scenarios, we find the results to be similar to those presented here. $^{27}$

\section{Concluding remarks}

To summarize our results, we find that consistently across methods the synergistic effect of participation in both the MGNREGA and PDS reduces women's morbidity by 0.26 to 0.3 days - this constitutes upto $28 \%$ reduction relative to the baseline average for women in the comparison group. Women's BMI improves only if they are in states that implement these programs well. Some specifications suggest that perhaps women who themselves work in the MGNREGA in treated households have worse BMI, likely due to the physically demanding nature of the MGNREGA. For children, we find on the other hand, that those belonging to households participating in both are associated with higher BMI-for-age scores (by 0.13 to 0.16 standard deviations), but there are no impacts on morbidity. The effects on children are less robust across methods and more complex. For example, we find that the improvements in BMI-for-age are positive (0.21 standard deviations), though weak, in households where both women and men work on the MGNREGA. We find likewise weak indications of worsening of morbidity when only men in the household work on the MGNREGA. We also find suggestive evidence that synergistic benefits accrue disproportionately to those located closer to health facilities. To our knowledge, this paper is the first to examine the synergistic effects of multiple social protection programs.

We started out askng if social protection programs can effectively take advantage of the interlinkages between the various SDG goals and put these synergies into practice. Our paper offers evidence that this faith is not misplaced: progammes aimed at reducing poverty and hunger can deliver health and nutrition impacts. At the same time, it also highlights that programs targeting households can have complex and heterogeneous impacts on individuals within the household, suggesting that for

\footnotetext{
${ }^{27}$ Results are available on request.
} 
social protection programs to be effective in addressing multiple SDG goals, we would need these to be both nutrition and gender sensitive.

\section{References}

Abadie, A. (2005). Semiparametric difference-in-differences estimators. The Review of Economic Studies, 72(1), pp.1-19. https://doi.org/10.1111/0034-6527.00321

Alderman, H., Haddad, L., \& Hoddinott, J. (1997) Intrahousehold Resource Allocation in Developing Countries, Baltimore: Johns Hopkins University Press.

Behrman, J. R. (1997). Intrahousehold distribution and the family. Handbook of population and family economics, 1, 125-187.Gulf Professional Publishing, https://doi.org/10.1016/S1574-003X(97)80021-9

Bhatia, R, Chinoy, SL, Kaushish, B, Puri, J, Chahar, VS and Waddington, H, (2016). Examining the evidence on the effectiveness of India's rural employment guarantee act, 3ie Working Paper 27. New Delhi: International Initiative for Impact Evaluation (3ie)

BMZ (2017). Social protection for equitable development. BMZ position paper 09/2017, Federal Ministry for Economic Cooperation and Development (BMZ), Bonn and Berlin, Germany.

Brown, Cait, Rossella Calvi, and Jacob Penglase (2019). Sharing the Pie:

Undernutrition, Intra-household Allocation, and Poverty. Working Paper, Central European University, School of Public

Policy. https://drive.google.com/file/d/1dwiC1ZshZ71IT2A7wAOtmUCZEWT2J7ca $\underline{\text { lview }}$

Brown, Cait, Martin Ravallion and Dominique van de Walle (2019). Most of Africa's nutritionally-deprived women and children are not found in poor households." The Review of Economics and Statistics, 101:4, 631-644. https://doi.org/10.1162/rest_a_00800

Cluver, L. D., Orkin, F. M., Meinck, F., Boyes, M. E., Yakubovich, A. R., \& Sherr, L. (2016). Can social protection improve sustainable development goals for adolescent health?. PLoS one, 11(10),. https://doi.org/10.1371/journal.pone.0164808

Dasgupta, A. (2017). Can Major Public Works Policy Buffer Negative Shocks in Early Childhood? Evidence from Andhra Pradesh, India. Economic Development and Cultural Change 65, no. 4 (July 2017): 767-804. https://doi.org/10.1086/691992

Deininger, K., \& Liu, Y. (2019). Heterogeneous welfare impacts of National Rural Employment Guarantee Scheme: Evidence from Andhra Pradesh, India. World Development, 117, 98-111. https://doi.org/10.1016/j.worlddev.2018.12.014 
Deolalikar A (1988): Nutrition and labor productivity in agriculture: Estimates for rural south India. Review of Economics and Statistics. 70, 406-413. doi: 10.2307/1926778

Desai, S. and Vanneman, R., 2015. Enhancing Nutrition Security via India's National Food Security Act: Using an Axe instead of a Scalpel?. In India Policy Forum:[papers]. India Policy Forum. Conference (Vol. 11, p. 67). NIH Public Access.

Gaiha, R, Kulkarni. V.S., Pandey, M.K. and Imai, K.S, (2010). National Rural Employment Guarantee Scheme, poverty and prices in rural India. Journal of Asian and African Studies, 45, pp.645-69. https://doi.org/10.1177\%2F0021909610383365

Holmes, R, S Rath and N Sadana (2011): “An Opportunity for Change? Gender Analysis of the Mahatma Gandhi National Rural Employment Guarantee Act", Project Briefing 53, Overseas Development Institute. [S[E:

Houngbedji, K. (2015). Abadie's Semiparametric Difference-in-Difference Estimator. $\begin{array}{lllll}\text { The Stata } & \text { Journal, } & \text { 482-490. }\end{array}$ https://doi.org/10.1177\%2F1536867X1601600213

Imbert, C., \& Papp, J. (2015). Labor market effects of social programs: Evidence from india's employment guarantee. American Economic Journal: Applied Economics, 7(2), 233-63. DOI: 10.1257/app.20130401

Jha, R., S.Bhattacharyya \& R.Gaiha (2011). Social safety nets and nutrient deprivation: An analysis of the National Rural Employment Guarantee Program and the Public Distribution System in India. Journal of Asian Economics , 22, 189-201. https://doi.org/10.1016/j.asieco.2010.11.004

Kanbur, R., (2015). "Mitigating risk: Social protection and the rural poor," in: 20142015 Global Food Policy Report, International Food Policy Research Institute (IFPRI), Washington.

Kaul, T. (2014). Household Responses to Food Subsidies: Evidence from India, Economic Development and Cultural Change 67, no. 1 (October 2018): 95-129. https://doi.org/10.1086/697553

Khera, R. (2011a). Revival of the public distribution system: Evidence and explanations. Economic and Political Weekly, 46 (44 \& 45), 36-50.

Khera, R. (ed.) (2011b), Battle for Employment Guarantee, Oxford University Press.

Khera, R., \& Nayak, N. (2009). Women Workers and perceptions of the National rural employment Guarantee act. Economic and Political Weekly, 49-57. 
Krishnamurthy, P., Pathania, V., \& Tandon, S. (2017). Food price subsidies and nutrition: evidence from state reforms to India's public distribution system. Economic Development and Cultural Change, 66(1), 55-90. https://doi.org/10.1086/694033

Kulkarni, B., Shatrugna, V., \& Balakrishna, N. (2006). Maternal lean body mass may be the major determinant of birth weight: a study from India. European journal of clinical nutrition, 60(11), 1341. https://doi.org/10.1038/sj.ejcn.1602461

Kumar, P. and P.K. Joshi. (2013). Household Consumption Pattern and Nutritional Security among Poor Rural Households: Impact of the MGNREGA. Agricultural Economics Research Review , 26 (1), 73-82.

Lentz, E.C., Narayanan, S., and De, Anuradha. (2019). Last and least: Findings on intrahousehold undernutrition from participatory research in South Asia."Social Science and Medicine. 232:316-323. https://doi.org/10.1016/j.socscimed.2019.05.024

Liu, Y. and C.B.Barrett (2013) Heterogeneous Pro- Poor Targeting in India's Mahatma Gandhi National Rural Employment Guarantee Scheme, Economic and Political Weekly, Vol 48(9\&10):46-53.

Nair, M., P.Ariana, E.Ohuma, R.Gray, B.De Stavola and P.Webster. (2013). Effect of the Mahatma Gandhi National Rural Employment Guarantee Act (MGNREGA) on Malnutrition of Infants in Rajathan, India: A Mixed Methods Study. PLoS ONE , 8 (9), 1-14. https://doi.org/10.1371/journal.pone.0075089

Narayanan, S., \& Das, U. (2014). Women participation and rationing in the employment guarantee scheme. Economic and Political Weekly, 49(46), 46-53.

Narayanan, S. and Gerber, N. (2017). Safety Nets for Food and Nutritional Security in India Global Food Security, 15: 65-76. https://doi.org/10.1016/j.gfs.2017.05.001

Narayanan, S., Gerber, N., Rathore,U. Naraparaju.K. (2017). Can social safety nets protect public health? The effect of India's workfare and foodgrain subsidy programs on anemia. ZEF Discussion Paper 245, Bonn, Germany. Avaliable at: https://www.zef.de/fileadmin/user_upload/zef_dp_245.pdf

Niti Aayog (2016). Evaluation Study on the Role of Public Distribution System in Shaping Household and Nutritional Security India, DMEO Report No.233, Niti Aayog, Government of India, December 2016. Available at: https://niti.gov.in/writereaddata/files/document_publication/Final\%20PDS\%20Report -new.pdf

Pingali, P., Mittra, B., \& Rahman, A. (2017). The bumpy road from food to nutrition security-Slow evolution of India's food policy. Global food security, 15, 77-84. https://doi.org/10.1016/j.gfs.2017.05.002

Rahman, A. (2014). Revival of rural public distribution system. Economic and Political Weekly, 49(20), 62-68. 
Ruel, M., H. Alderman and the Maternal and Child Nutrition Study Group. (2013). Nutrition-sensitive interventions and programs: how can they help to accelerate progress in improving maternal and child nutrition? The Lancet, Vol. 383: 536-551. https://doi.org/10.1016/S0140-6736(13)60843-0

Satyanarayana, K., Venkataramana, Y., \& Rao, S. M. (1989). Nutrition and work performance: studies carried out in India. In Proceedings of XIVth International Congress of Nutrition. Seoul, Korea: Korean Nutrition Society (pp. 98-99).

Sharma, A. (2015). "Employment Guarantee Scheme and Child Health Outcome: Evidence from MGNREGA Using Propensity Score Matching Analysis."Available at SSRN 2708549 (2015).

Sukhtankar, S. (2016). India's National Rural Employment Guarantee Scheme: What Do We Really Know about the World's Largest Workfare Program?. In India Policy Forum (Vol. 13, pp. 2009-10).

Thampi, A. (2016). The Impact of the Public Distribution System in India. Indian Journal of Human Development, 10(3), 353-365. https://doi.org/10.1177\%2F0973703016685792

Thomas, D. (1990). Intra-household resource allocation: An inferential approach. Journal of human resources, 25(4): 635-664. DOI: 10.2307/145670

United Nations (2018) Advancing the 2030 Agenda: Interlinkages and Common Themes at the HLPF 2018 A UN-DESA Report of the Meeting,of experts in preparation fo the HLPF 2018: Transformation towards sustainable United Nations Headquarters, New York, 25-26 January 2018.

Uppal, V. (2009). Is the NREGS a Safety Net for Children: Studying the access to the National Rural Employment Guarantee Scheme for the Young Lives families and its impact on child outcomes in Andhra Pradesh. MSc Thesis- Young Lives student paper, University of Oxford..Available at: http://knowledge. nrega. net/859/1/Is_the_NREGS_a_Safety_Net_for_Children.pdf (2009). 